Appl. Set-Valued Anal. Optim. 3 (2021), No. 1, pp. 3-20

Available online at http://asvao.biemdas.com

https://doi.org/10.23952/asvao.3.2021.1.02

\title{
APPROXIMATION OF COMMON SOLUTIONS FOR A FINITE FAMILY OF GENERALIZED DEMIMETRIC MAPPINGS AND MONOTONE INCLUSION PROBLEMS IN CAT $(0)$ SPACES
}

\author{
G.C. UGWUNNADI ${ }^{1,2 *}$, C.C. OKEKE ${ }^{2}$ \\ ${ }^{1}$ Department of Mathematics, University of Eswatini, Kwaluseni, Eswatini \\ ${ }^{2}$ Department of Mathematics and Applied Mathematics, \\ Sefako Makgatho Health Sciences University, Pretoria, South Africa
}

\begin{abstract}
In this paper, we introduce a modified Halpern-Mann algorithm and study the strong convergence of the algorithm for approximating common solution of a finite family of monotone inclusion problems and a finite family of generalized demimetric mappings in complete CAT $(0)$ spaces. Some applications are also considered.
\end{abstract}

Keywords. Monotone operator; Fixed point; Zero point; Strong Convergence; Hadamard Space.

\section{INTRODUCTION}

The inclusion problem (IP) with a set-valued operator $A$ in a Hilbert space $H$ is consists of finding

$$
x \in H \text { such that } 0 \in A x .
$$

The solution set of problem (1.1) is denoted by $A^{-1}(0)$. This problem is closely related to many real-world problems, such as signal processing, medical imaging, and machine learning $[1,2,3,4,5]$ and the references therein.

In 1970, Martinet [6] first studied solutions of problem (1.1) in Hilbert spaces. Later, Rockafellar [7] further studied the inclusion problem by introducing the following iterative algorithm in a Hilbert space $H$

$$
x_{1} \in H, \quad x_{n}=J_{\lambda_{n}}\left(x_{n-1}\right), \quad \forall n \geq 1,
$$

where $\left\{\lambda_{n}\right\}$ is a sequence of positive real numbers and $J_{\lambda}$ is the resolvent of $A$ defined by $J_{\lambda}=$ $(I+\lambda A)^{-1}$ for $\lambda>0$, and $A$ is a maximal monotone operator in $H$. The algorithm is called the Proximal Point Algorithm (PPA). Rockafellar proved that the sequence $\left\{x_{n}\right\}$ generated by (1.2) converges weakly to a solution of (1.1) provided $\lambda_{n} \geq \lambda>0$ for each $n \geq 1$. The generalizations and modified versions of the proximal point algorithm in Hilbert were studied by many authors recently; see, e.g., $[8,9,10,11,12,13]$ and the references therein.

${ }^{*}$ Corresponding author.

E-mail addresses: ugwunnadi4u@yahoo.com (G.C. Ugwunnadi), chibueze.okeke87@ yahoo.com (C.C. Okeke) Received April 28, 2020; Accepted July 30, 2020. 
On the other hand, by using the duality mapping theory introduced by Kakavandi and Amini [14], Khatibzadeh and Ranjbar [15] introduced and study solutions of problem (1.1) via the proximal point algorithm in complete CAT(0) space $X$

$$
x_{1} \in X, \quad x_{n}=J_{\lambda_{n}}^{A} x_{n-1}, \quad \forall n \geq 1,
$$

where $\left\{\lambda_{n}\right\}$ is a sequence of positive real numbers such that $\sum_{n=1}^{\infty} \lambda_{n}=\infty$.

Recently, Ranjbar and Khatibzadeh [16] proposed the following Mann-type and Halpern-type proximal point algorithms in complete CAT(0) spaces for finding a solution of problem (1.1)

$$
x_{1} \in X, \quad x_{n+1}=\alpha_{n} x_{n} \oplus\left(1-\alpha_{n}\right) J_{\lambda_{n}}^{A} x_{n}, \quad \forall n \geq 1,
$$

and

$$
u, x_{1} \in X, \quad x_{n+1}=\alpha_{n} u \oplus\left(1-\alpha_{n}\right) J_{\lambda_{n}}^{A} x_{n}, \quad \forall n \geq 1,
$$

where $\left\{\lambda_{n}\right\} \subset(0, \infty)$ and $\left\{\alpha_{n}\right\} \subset[0,1]$. They obtained a $\Delta$-convergence result using the Manntype proximal point algorithm and they also obtained a strong convergence result using the Halpern-type proximal point algorithm.

Let $X$ be a metric space, and let $C$ be a nonempty closed and convex subset of $X$. A point $x \in C$ is called a fixed point of a mapping $T: C \rightarrow X$ provided $T x=x$. We denote by $F(T):=\{x \in C$ : $T x=x\}$ the set of fixed points of $T$. Recently, many authors studied fixed points of nonlinear operators in convex metric spaces; see, e.g., $[17,18,19,20]$ and the references therein.

Recently, Aremu et al. [21] and Ugwunnadi et al. [22] used the concept of quasilinearization to define new operators in CAT(0) spaces as follows.

Definition 1.1. Let $X$ be a complete CAT(0) space, and let $C$ be a nonempty closed and convex subset of $X$. The mapping $T$ from $C$ into $X$ is said to be

(i) $k$-demimetric (see [21]) if $F(T) \neq \emptyset$ and there exists $k \in(-\infty, 1)$ such that

$$
\langle\overrightarrow{x p}, \overrightarrow{x T x}\rangle \geq \frac{1-k}{2} d^{2}(x, T x), \text { for all } x \in X \text { and } p \in F(T) .
$$

(ii) $\theta$-generalized demimetric (see [22]) if $F(T) \neq \emptyset$ and there exists $\theta \in \mathbb{R}$ such that

$$
d^{2}(x, T x) \leq \theta\langle\overrightarrow{x u}, \overrightarrow{x T x}\rangle
$$

for all $x \in C$ and $u \in F(T)$.

Remark 1.1. It is clear in Definition 1.1 that, for any $k \in(-\infty, 1)$, a $k$-demimetric mapping is $\frac{2}{1-k}$-generalized demimetric. Also, for $\theta>0$, a $\theta$-generalized demimetric is $\left(1-\frac{2}{\theta}\right)$ demimetric.

Motivated by the above results, in this paper, we study a modified Halpern-Mann type algorithm for approximating common solution of a finite family of monotone inclusion problems and a finite family of generalized demimetric mappings. We also obtain a strong convergence theorem in Hadamard spaces. Our results unify and compliments many results in the current literature. 


\section{PRELIMINARIES}

A geodesic path joining two elements $x, y$ in a metric space $X$ is an isometry $c:[0, l] \rightarrow X$, where $d(x, y)=l$ such that $c(0)=x$ and $c(l)=y$. The image of a geodesic path is called a geodesic segment. A metric space for which every two points can be joined by a geodesic segment is called a geodesic space. We say that a metric space $X$ is uniquely geodesic if every two points of $X$ are joined by only one geodesic segment (i.e., CAT(0) space). The examples of $\operatorname{CAT}(0)$ spaces are Euclidean spaces $\mathbb{R}^{n}$ and Hilbert spaces. For more details, please see [23, 24, 25, 26]. Complete CAT $(0)$ spaces are often called Hadamard spaces.

Let $(1-t) x \oplus$ ty denote the unique point $z$ in the geodesic segment joining $x$ to $y$ for each $x, y$ in a CAT(0) space such that $d(z, x)=t d(x, y)$ and $d(z, y)=(1-t) d(x, y)$, where $t \in[0,1]$. Let $[x, y]:=\{(1-t) x \oplus t y: t \in[0,1]\}$. Then, a subset $C$ of $X$ is convex if $[x, y] \subseteq C$ for all $x, y \in C$.

In 2008, Breg and Nikolaev [27] introduced the concept of quailinearization mappings in CAT(0) spaces. They denoted a pair $(a, b) \in X \times X$ by $\overrightarrow{a b}$, which they called a vector and defined a mapping $\langle.,\rangle:.(X \times X) \times(X \times X) \rightarrow \mathbb{R}$ by

$$
\langle\overrightarrow{a b}, \overrightarrow{c d}\rangle=\frac{1}{2}\left(d^{2}(a, d)+d^{2}(b, c)-d^{2}(a, c)-d^{2}(b, d)\right),(a, b, c, d \in X),
$$

which is called the quasilinearization mapping. It is easy to verify that $\langle\overrightarrow{a b}, \overrightarrow{a b}\rangle=d^{2}(a, b)$, $\langle\overrightarrow{b a}, \overrightarrow{c d}\rangle=-\langle\overrightarrow{a b}, \overrightarrow{c d}\rangle,\langle\overrightarrow{a b}, \overrightarrow{c d}\rangle=\langle\overrightarrow{a e}, \overrightarrow{c d}\rangle+\langle\overrightarrow{e b}, \overrightarrow{c d}\rangle$ and $\langle\overrightarrow{a b}, \overrightarrow{c d}\rangle=\langle\overrightarrow{c d}, \overrightarrow{a b}\rangle$ for all $a, b, c, d, e \in$ $X$. It has been established that a geodesically connected metric space is a CAT( 0$)$ space if and only if it satisfies the Cauchy-Schwartz inequality (see [27]). Recall that the space $X$ is said to satisfy the Cauchy-Swartz inequality if $\langle\overrightarrow{a b}, \overrightarrow{c d}\rangle \leq d(a, b) d(c, d) \forall a, b, c, d \in X$. Let $X$ be a complete CAT(0) space, and let $X^{*}$ be its dual space. A multivalued operator $A: X \rightarrow 2^{X^{*}}$ with domain $\mathbb{D}(A):=\{x \in X: A x \neq \emptyset\}$ is monotone if and only if, for all $x, y \in \mathbb{D}(A), x^{*} \in A x, y^{*} \in$ Ay,

$$
\left\langle x^{*}-y^{*}, \overrightarrow{y x}\right\rangle \geq 0 \text { (see [15]). }
$$

The resolvent of the operator $A$ of order $\lambda>0$ is the multivalued mapping $J_{\lambda}^{A}: X \rightarrow 2^{X}$ defined in [15] as

$$
J_{\lambda}^{A}(x):=\left\{z \in X \mid\left[\frac{1}{\lambda} \overrightarrow{z x}\right] \in A z\right\}
$$

The operator $A$ satisfies the range condition if for every $\lambda>0, \mathbb{D}\left(J_{\lambda}^{A}\right)=X$ (see [15]). For simplicity, we shall write $J_{\lambda}$ for the resolvent of a monotone operator $A$. Since our main contribution in this paper is on Hadamard spaces for monotone inclusion problems, it is worthwhile to provide a detailed proof of example of a monotone mapping in Hadamard spaces.

Example 2.1. [28] Let $X=\mathbb{R}^{2}$ be an $\mathbb{R}$-tree with the radical metric $d_{r}$, where $d_{r}(x, y)=d(x, y)$ if $x$ and $y$ are situated on the euclidean straight line passing through the origin and

$$
d_{r}(x, y)=d(x, 0)+d(y, 0):=\|x\|+\|y\|,
$$

otherwise let $p=(1,0)$ and $X=B \cup C$, where

$$
B=\{(h, 0): h \in[0,1]\} \text { and } C=\{(h, k): h+k=1, h \in[0,1)\} .
$$


Then, $\left(X, d_{r}\right)$ is an Hadamard space and $X^{*}$, which is a space of element $[\overrightarrow{t a b}]$ such that

$$
[\overrightarrow{t a b}]=\left\{\begin{array}{l}
\{\overrightarrow{s c d}: c, d \in B, s \in \mathbb{R}, t(\|b\|-\|a\|)=S(\|d\|-\| c \mid)\} a, b, \in B, \\
\{\overrightarrow{s c d}: c, d \in C \in\{0\}, s \in \mathbb{R}, t(\|b\|-\|a\|)=s(\|d\|-\|c\|),\} a, b \in C \cup\{0\}, \\
\{\overrightarrow{t a b}\}
\end{array}\right.
$$

is the dual space of $X$ (see [29]). Now, defined $A: X \rightarrow 2^{X^{*}}$ by

$$
A x:= \begin{cases}\{[\overrightarrow{0 p}]\}, & x \in B, \\ \{[\overrightarrow{0 p}],[\overrightarrow{0 x}]\}, & x \in C .\end{cases}
$$

Then $A$ is a multivalued monotone operator. To see this we consider the cases:

(I) If $x, y \in B$, then $A x=A y=\{[\overrightarrow{0 p}]\}$ and $x^{*}=y^{*}=[\overrightarrow{0 p}]$. So, $\left\langle x^{*}-y^{*}, \overrightarrow{y x}\right\rangle=0 \geq 0$.

(II) If $x, y \in C$, then $A x=\{[\overrightarrow{0 p}],[\overrightarrow{0 x}]\}$ and $A y=\{[\overrightarrow{0 p}],[\overrightarrow{0 y}]\}$.

(i) If $x^{*}=y^{*}=[\overrightarrow{0 p}]$; then $\left\langle x^{*}-y^{*}, \overrightarrow{y x}\right\rangle=0 \geq 0$.

(ii) If $x^{*}=[\overrightarrow{0 x}]$ and $y^{*}=[\overrightarrow{0 y}]$, then

$$
\begin{aligned}
\left\langle x^{*}-y^{*}, \overrightarrow{y x}\right\rangle & =\langle\overrightarrow{y p}, \overrightarrow{y x}\rangle \\
& =\frac{1}{2}\left(d_{r}^{2}(y, x)+d_{r}^{2}(p, y)-d_{r}^{2}(p, x)\right) \\
& =\frac{1}{2}\left((\|y\|+\|x\|)^{2}+(1+\|y\|)^{2}-(1+\|x\|)^{2}\right) \\
& \geq 0(\text { since } 1 / \sqrt{2} \leq\|x\| \cdot\|y\| \leq 1) .
\end{aligned}
$$

(iv) If $x^{*}=[\overrightarrow{0 x}]$ and $y^{*}=[\overrightarrow{0 p}]$, then $\left\langle x^{*}-y^{*}, \overrightarrow{y x}\right\rangle=\langle\overrightarrow{p x}, \overrightarrow{y x}\rangle$, which is similar to (iii).

(III) If $x \in B, y \in C$. Then $A x=\{[\overrightarrow{0 p}]\}, A y=\{[\overrightarrow{0 p}],[\overrightarrow{0 y}]\}$.

(i) If $x^{*}=y^{*}=[\overrightarrow{0 p}]$, then $\left\langle x^{*}-y^{*}, \overrightarrow{y x}\right\rangle=0 \geq 0$.

(ii) If $x^{*}=[\overrightarrow{0 p}]$ and $y^{*}=[\overrightarrow{o y}]$, then

$$
\begin{aligned}
\left\langle x^{*}-y^{*}, \overrightarrow{y x}\right\rangle & =\langle\overrightarrow{y p}, \overrightarrow{y x}\rangle \\
& =\frac{1}{2}\left(d_{r}^{2}(y, x)+d_{r}^{2}(p, y)-d_{r}^{2}(p, x)\right) \\
& \geq 0
\end{aligned}
$$

due to $d(p, x) \leq 1 \leq d(p, y)$. Thus, $A$ is monotone.

We state some known and useful results which will be needed in the proof of our main theorem.

Lemma 2.1. [30] Let $X$ be a CAT(0) space, $x, y, z \in X$ and $\lambda \in[0,1]$. Then

(i) $d(\lambda x \oplus(1-\lambda) y, z) \leq \lambda d(x, z)+(1-\lambda) d(y, z)$.

(ii) $d^{2}(\lambda x \oplus(1-\lambda) y, z) \leq \lambda d^{2}(x, z)+(1-\lambda) d^{2}(y, z)-\lambda(1-\lambda) d^{2}(x, y)$.

Let $\left\{x_{n}\right\}$ be a bounded sequence in a complete CAT(0) space $X$. For $x \in X$, we set

$$
r\left(x,\left\{x_{n}\right\}\right)=\limsup _{n \rightarrow \infty} d\left(x, x_{n}\right) .
$$

The asymptotic radius $r\left(\left\{x_{n}\right\}\right)$ of $\left\{x_{n}\right\}$ is given by

$$
r\left(\left\{x_{n}\right\}\right)=\inf \left\{r\left(x,\left\{x_{n}\right\}\right): x \in X\right\},
$$


and the asymptotic center $A\left(\left\{x_{n}\right\}\right)$ of $\left\{x_{n}\right\}$ is the set

$$
A\left(\left\{x_{n}\right\}\right)=\left\{x \in X: r\left(x,\left\{x_{n}\right\}\right)=r\left(\left\{x_{n}\right\}\right)\right\} .
$$

It is well known that, in a CAT(0) space, $A\left(\left\{x_{n}\right\}\right)$ consists of exactly one point ([31]). A sequence $\left\{x_{n}\right\}$ in $X$ is said to be $\triangle$-convergent to $x \in X$, denoted by $\triangle-\lim _{n} x_{n}=x$ if $x$ is the unique asymptotic center of $\left\{u_{n}\right\}$, for every subsequence $\left\{u_{n}\right\}$ of $\left\{x_{n}\right\}$.

Lemma 2.2. [32] If $\left\{x_{n}\right\}$ is a bounded sequence in a closed and convex subset $C$ of a complete $C A T(0)$ space, then the asymptotic center of $\left\{x_{n}\right\}$ is in $C$.

Let $\left\{x_{n}\right\}$ be a bounded sequence in a complete CAT(0) space $X$, and let $C$ be a closed and convex subset of $X$, which contains $\left\{x_{n}\right\}$. We employ the notation

$$
\left\{x_{n}\right\} \rightarrow w \Leftrightarrow \limsup _{n \rightarrow \infty} d\left(x_{n}, w\right)=\inf _{x \in C}\left(\limsup _{n \rightarrow \infty} d\left(x_{n}, x\right)\right) .
$$

We note that $\left\{x_{n}\right\} \rightarrow w$ if and only if $A\left(\left\{x_{n}\right\}\right)=\{w\}$ (see [33]).

Lemma 2.3. [34] Let $X$ be a CAT(0) space. For any $u, v, \in X$ and $t \in(0,1)$, let $u_{t}=t u \oplus(1-t) v$. Then, for all $x, y \in X$,

(i) $\left\langle\overrightarrow{u_{t} x}, \overrightarrow{u_{t} y}\right\rangle \leq t\left\langle\overrightarrow{u x}, \overrightarrow{u_{t} y}\right\rangle+(1-t)\left\langle\overrightarrow{v x}, \overrightarrow{u_{t} y}\right\rangle$;

(ii) $\left\langle\overrightarrow{u_{t} x}, \overrightarrow{u y}\right\rangle \leq t\langle\overrightarrow{u x}, \overrightarrow{u y}\rangle+(1-t)\langle\overrightarrow{v x}, \overrightarrow{u y}\rangle$

$$
\text { and }\left\langle\overrightarrow{u_{t} x}, \overrightarrow{v y}\right\rangle \leq t\langle\overrightarrow{u x}, \overrightarrow{v y}\rangle+(1-t)\langle\overrightarrow{v x}, \overrightarrow{v y}\rangle \text {. }
$$

Lemma 2.4. [33] If $\left\{x_{n}\right\}$ is a bounded sequence in a closed and convex subset $C$ of a complete $C A T(0)$ space, then $\triangle-\lim _{n \rightarrow \infty} x_{n}=p$ implies that $\left\{x_{n}\right\} \rightarrow p$.

Theorem 2.1. [15] Let $X$ be a CAT(0) space and let $J_{\lambda}^{A}$ be the resolvent of the operator $A$ of order $\lambda$. We have

(i) For any $\lambda>0, \mathbb{R}\left(J_{\lambda}^{A}\right) \subset \mathbb{D}(A), F\left(J_{\lambda}^{A}\right)=A^{-1}(0)$.

(ii) If $A$ is monotone then $J_{\lambda}^{A}$ is a single-valued and firmly nonexpansive mapping.

The following remark is a consequence of Theorem 2.1.

Remark 2.1. (see [35]) If $X$ is a CAT(0) space and $J_{\lambda}^{A}$ is the resolvent of a monotone operator $A: X \rightarrow 2^{X^{*}}$ of order $\lambda>0$, then

$$
d^{2}\left(u, J_{\lambda}^{A} x\right)+d^{2}\left(J_{\lambda}^{A} x, x\right) \leq d^{2}(u, x)
$$

for all $u \in A^{-1}(0)$ and $x \in \mathbb{D}\left(J_{\lambda}^{A}\right)$.

Proof. Indeed, for any $u \in A^{-1}(0), x \in \mathbb{D}\left(J_{\lambda}^{A}\right)$ and $\lambda>0$, we obtain from Theorem 2.1 (i) and (ii) that

$$
\begin{aligned}
d^{2}\left(J_{\lambda}^{A} x, u\right) & \leq\left\langle\overrightarrow{J_{\lambda}^{A} x u}, \overrightarrow{x u}\right\rangle \\
& =\frac{1}{2}\left(d^{2}\left(J_{\lambda}^{A} x, u\right)+d^{2}(u, x)-d^{2}\left(J_{\lambda}^{A} x, x\right)\right)
\end{aligned}
$$

which implies

$$
d^{2}\left(u, J_{\lambda}^{A} x\right)+d^{2}\left(J_{\lambda}^{A} x, x\right) \leq d^{2}(u, x)
$$


Lemma 2.5. [36] Let $\left\{x_{n}\right\}$ be a sequence in a complete $C A T(0)$ space $X$, and $x \in X$. Then $\left\{x_{n}\right\}$ is $\triangle$-convergent to $x$ if and only if $\limsup _{n \rightarrow \infty}\left\langle\overrightarrow{x x_{n}}, \overrightarrow{x y}\right\rangle \leq 0$ for all $y \in X$.

Lemma 2.6. [19] Every bounded sequence in a complete CAT(0) spaces always has a convergent subsequence.

Lemma 2.7. [17] Let $C$ be a nonempty, closed and convex subset of CAT(0) space X. Let $\left\{x_{i}: i=1,2, \ldots, N\right\}$ be in $C$, and $\alpha_{1}, \alpha_{2}, \ldots, \alpha_{N} \in(0,1)$ such that $\sum_{i=1}^{N} \alpha_{i}=1$. Then the following inequality hold:

(i) $d\left(z, \bigoplus_{i=1}^{N} \alpha_{i} x_{i}\right) \leq \sum_{i=1}^{N} \alpha_{i} d\left(z, x_{i}\right)$ for all $z \in C$.

(ii) $d^{2}\left(z, \bigoplus_{i=1}^{N} \alpha_{i} x_{i}\right) \leq \sum_{i=1}^{N} \alpha_{i} d^{2}\left(z, x_{i}\right)-\sum_{i, j=1, i \neq j}^{N} \alpha_{i} \alpha_{j} d^{2}\left(x_{i}, x_{j}\right)$ for all $z \in C$.

Lemma 2.8. [37] Let C be a nonempty, convex subset of CAT (0) space X. Let $\left\{u_{i}: i=1,2, \ldots, N\right\}$ $\subset C$, and $\alpha_{1}, \alpha_{2}, \ldots, \alpha_{N} \in(0,1)$ such that $\sum_{i=1}^{N} \alpha_{i}=1$. Then the following inequalities hold:

$$
\begin{aligned}
\left\langle\overrightarrow{\bigoplus_{i=1}^{N}} \alpha_{i} u_{i} x, \overrightarrow{x y}\right\rangle & \leq \sum_{i=1}^{N} \alpha_{i}\left\langle\overrightarrow{u_{i} x}, \overrightarrow{x y}\right\rangle+\frac{1}{2}\left(\sum_{i=1}^{N} \alpha_{i} d^{2}\left(u_{i}, x\right)-d^{2}\left(\bigoplus_{i=1}^{N} \alpha_{i} u_{i}, x\right)\right) \\
& \leq \sum_{i=1}^{N} \alpha_{i}\left\langle\overrightarrow{u_{i} x}, \overrightarrow{x y}\right\rangle+\frac{1}{2} \sum_{i=1}^{N} \alpha_{i} d^{2}\left(u_{i}, x\right) .
\end{aligned}
$$

Lemma 2.9. [37] Let $X$ be a CAT(0) space and let $C$ a nonempty convex subset of $X$. Assume that $\left\{S_{i}\right\}_{i=1}^{N}: C \rightarrow X$ is a finite family of $k_{i}$-demimetric mapping with $k_{i} \in(-\infty, 1)$ for each $i \in\{1,2, \ldots, N\}$ such that $\bigcap_{i=1}^{N} F\left(S_{i}\right) \neq \emptyset$. Let $\left\{\alpha_{i}\right\}_{i=1}^{N}$ be a positive sequence with $\sum_{i=1}^{N} \alpha_{i}=1$. Then $\bigoplus_{i=1}^{N} \alpha_{i} S_{i}: C \rightarrow X$ is a k-demimetric mapping if $k:=\max \left\{k_{i}: i=1,2, \ldots, N,\right\} \leq 0$ and $F\left(\bigoplus_{i=1}^{N} \alpha_{i} S_{i}\right)=\bigcap_{i=1}^{N} F\left(S_{i}\right)$.

Definition 2.1. Let $C$ be a nonempty closed and convex subset of a complete CAT(0) space $X$. The metric projection $P_{C}: X \rightarrow C$ is defined by

$$
u=P_{C}(x) \Leftrightarrow d(u, x)=\inf \{d(y, x): y \in C\}, \text { for all } x \in X .
$$

Lemma 2.10. [27] Let $C$ be a nonempty closed and convex subset of complete CAT(0) space $X$. For any $x \in X$ and $u \in C, u=P_{C} x$ if and only if

$$
\langle\overrightarrow{y u}, \overrightarrow{u x}\rangle \geq 0 \text {. }
$$

Lemma 2.11. [22] Let $C$ be a nonempty closed and convex subset of a $C A T(0)$ space $X$ and let $T: C \rightarrow X$ be a $\theta$-generalized demimetric mapping with $\theta \in \mathbb{R}$. Then, it is closed and convex.

Lemma 2.12. [22] Let $C$ be a nonempty closed and convex subset of a $C A T(0)$ space $X$ and let $T: C \rightarrow X$ be a $\theta$-generalized demimetric mapping. Then, for any $\theta \in[0, \infty)$ and $k \in(0,1]$, $(1-k) I \oplus k T$ is $\theta k$-generalized demimetric from $C$ into $X$.

Lemma 2.13. [21] Let $X$ be a $C A T(0)$ space, $T: X \rightarrow X$ a k-demimetric mapping with $k \in$ $(-\infty, \lambda)$ with $\lambda \in(0,1)$ and $F(T) \neq \theta$. Suppose that $T_{\lambda} x:=(1-\lambda) \oplus \lambda T x$. Then $T_{\lambda}$ is quasinonexpansive mapping and $F\left(T_{\lambda}\right)=F(T)$.

Lemma 2.14. [34] Let $X$ be a complete $C A T(0)$ space. Then, for all $u, x, y \in X$, the following inequality holds:

$$
d^{2}(x, u) \leq d^{2}(y, u)+2\langle\overrightarrow{x y}, \overrightarrow{x u}\rangle \text {. }
$$


Lemma 2.15. [38] Let $X$ be a complete $C A T(0)$ space. For all $u, x, y \in X$ and $\alpha \in[0,1]$, let $z_{1}=\alpha x \oplus(1-\alpha) u$ and $z_{2}=\alpha y \oplus(1-\alpha) u$. Then

$$
\left\langle\overrightarrow{z_{1} z_{2}}, \overrightarrow{x z_{2}}\right\rangle \leq \alpha\langle\overrightarrow{x y}, \overrightarrow{x u}\rangle .
$$

Lemma 2.16. [39] If $\left\{a_{n}\right\}$ is a sequence of nonnegative real numbers satisfying the following inequality:

$$
a_{n+1} \leq\left(1-\alpha_{n}\right) a_{n}+\alpha_{n} \sigma_{n}+\gamma_{n}, n \geq 0
$$

where, $(i)\left\{\alpha_{n}\right\} \subset[0,1], \sum \alpha_{n}=\infty$; (ii) limsup $\sigma_{n} \leq 0$; (iii) $\gamma_{n} \geq 0 ;(n \geq 0)$ and $\sum \gamma_{n}<\infty$. Then, $a_{n} \rightarrow 0$ as $n \rightarrow \infty$.

Lemma 2.17. [40] If $\left\{a_{n}\right\}$ is a sequence of real numbers and there exists a subsequence $\left\{n_{i}\right\}$ of $\{n\}$ such that $a_{n_{i}}<a_{n_{i}+1}$ for all $i \in \mathbb{N}$, then there exists a nondecreasing sequence $\left\{m_{k}\right\} \subset \mathbb{N}$ such that $m_{k} \rightarrow \infty$ and the following properties are satisfied: $a_{m_{k}} \leq a_{m_{k}+1}$ and $a_{k} \leq a_{m_{k}+1}$. for all sufficiently large numbers $k \in \mathbb{N}$. In fact, $m_{k}=\max \left\{j \leq k: a_{j}<a_{j+1}\right\}$.

\section{MAin RESUlTS}

Theorem 3.1. Let $X$ be a complete $C A T(0)$ space with dual $X^{*}$ and let $C$ be a nonempty closed and convex subset of $X$. Let $\left\{T_{i}\right\}_{i=1}^{N}: C \rightarrow X$ be a finite family of $\theta_{i}$-generalized demimetric mapping and $\Delta$-demiclosd at 0 with $\theta_{i} \in(0, \infty)$ for each $i \in\{1,2, \ldots, N\}$. Let $A_{i}: X \rightarrow 2^{X^{*}}$ $(i=1,2, \ldots, N)$ be multivalued monotone mappings which satisfy the range condition. Assume that $\Upsilon:=\bigcap_{i=1}^{N} F\left(T_{i}\right) \cap\left(\bigcap_{i=1}^{N} A_{i}^{-1}(0)\right) \neq \emptyset$. Let $\left\{u_{n}\right\}$ be a sequence in $X$ such that $u_{n} \rightarrow u \in X$. Assume for $k \in(0, \gamma)$ with $\gamma \in(0,1)$ and $\theta_{i} k>0$. For any $x_{1} \in X$, let $\left\{x_{n}\right\}$ in $X$ be a sequence generated by

$$
\left\{\begin{array}{l}
y_{n}=J_{\lambda}^{N} \circ J_{\lambda}^{N-1} \circ \cdots \circ J_{\lambda}^{2} \circ J_{\lambda}^{1} x_{n}, \\
z_{n}=(1-\gamma) y_{n} \oplus \gamma\left[\oplus_{i=1}^{N} \xi_{i}\left((1-k) \oplus k T_{i}\right) y_{n}\right], \\
x_{n+1}=\alpha_{n} u_{n} \oplus \beta_{n} x_{n} \oplus \sigma_{n} z_{n},
\end{array}\right.
$$

where $\lambda \in(0, \infty),\left\{\alpha_{n}\right\},\{\sigma\},\left\{\beta_{n}\right\}$ and $\left\{\xi_{i}\right\}_{i=1}^{N}$ are sequences in $(0,1)$ satisfying the following conditions

(i) $\lim _{n \rightarrow \infty} \alpha_{n}=0$ and $\sum_{i=1}^{\infty} \alpha_{n}=\infty$;

(ii) $\alpha_{n}+\beta_{n}+\sigma_{n}=1$.

Then $\left\{x_{n}\right\}$ converges strongly to $x^{*} \in \Upsilon$.

Proof. Let $S_{i}=(1-k) \oplus k T_{i}$ and $W_{N}=\bigoplus_{i=1}^{N} \xi_{i} S_{i}$. Then we can rewrite algorithm (3.1) as:

$$
\left\{\begin{array}{l}
y_{n}=J_{\lambda}^{N} \circ J_{\lambda}^{N-1} \circ \cdots \circ J_{\lambda}^{2} \circ J_{\lambda}^{1} x_{n}, \\
z_{n}=(1-\gamma) y_{n} \oplus \gamma W_{N} y_{n} \\
x_{n+1}=\alpha_{n} u_{n} \oplus \beta_{n} x_{n} \oplus \sigma_{n} z_{n}
\end{array}\right.
$$

since $T_{i}: C \rightarrow X$ is $\theta_{i}$-generalized demimetric, by Lemma 2.11, we have that $F\left(T_{i}\right)$ is closed and convex for each $i \in\{1,2, \cdots, N\}$. Also, $J_{\lambda}^{i}$ is firmly nonexpansive by Theorem 2.1 and hence nonexpansive for each $i=1,2, \ldots, N$. Therefore $F\left(J_{\lambda}^{i}\right)$ is closed and convex for each $i=1,2, \ldots, N$. Hence, $\bigcap_{i=1}^{N} F\left(T_{i}\right) \cap\left(\bigcap_{i=1}^{N} A_{i}^{-1}(0)\right)$ is nonempty closed and convex. Therefore, $P_{\bigcap_{i=1}^{N} F\left(T_{i}\right) \cap\left(\bigcap_{i=1}^{N} A_{i}^{-1}(0)\right)}$ is well defined. Furthermore, $T_{i}$ is $\theta_{i}$-generalized demimetric with $\theta_{i} \in(0, \infty)$ for each $i \in\{1,2, \ldots, N\}$. So, for any $k \in(0, \gamma)$, with $\gamma \in(0,1)$, we find from 
Lemma 2.12 that $S_{i}$ is $\theta_{i} k$-generalized demimetric for each $i$. By Remark 1.1, we have that $S_{i}$ is $\left(1-\frac{2}{\theta_{i} k}\right)$-demimetric. We obtain from Lemma 2.9 that $W_{N}=\bigoplus_{i=1}^{N} \xi_{i} S_{i}$ is demimetric. It follows by Lemma 2.13 that $V_{N}:=(1-\gamma) \oplus \gamma W_{N}$ is quasi-nonexpansive and $F\left(V_{N}\right)=F\left(W_{N}\right)=$ $\bigcap_{i=1}^{N} F\left(S_{i}\right)=\bigcap_{i=1}^{N} F\left(T_{i}\right)$. Let $p \in \Upsilon, \Psi_{\lambda}^{N}:=J_{\lambda}^{N} \circ J_{\lambda}^{N-1} \circ \cdots \circ J_{\lambda}^{2} \circ J_{\lambda}^{1}$, where $\Psi_{\lambda}^{0}=I$. Then by the definition of $\left(y_{n}\right)$ in (3.2) and Remark 2.1, we obtain

$$
\begin{aligned}
d^{2}\left(y_{n}, p\right) \leq & d^{2}\left(\Psi_{\lambda}^{N-1} x_{n}, p\right)-d^{2}\left(\Psi_{\lambda}^{N-1} x_{n}, y_{n}\right) \\
\leq & d^{2}\left(\Psi_{\lambda}^{N-2} x_{n}, p\right)-d^{2}\left(\Psi_{\lambda}^{N-2} x_{n}, \Psi_{\lambda}^{N-1} x_{n}\right)-d^{2}\left(\Psi_{\lambda}^{N-1} x_{n}, y_{n}\right) \\
\leq & d^{2}\left(\Psi_{\lambda}^{N-3} x_{n}, p\right)-d^{2}\left(\Psi_{\lambda}^{N-3} x_{n}, \Psi_{\lambda}^{N-2} x_{n}\right)-d^{2}\left(\Psi_{\lambda}^{N-2} x_{n}, \Psi_{\lambda}^{N-1} x_{n}\right) \\
& -d^{2}\left(\Psi_{\lambda}^{N-1} x_{n}, y_{n}\right) \\
\leq & d^{2}\left(x_{n}, p\right)-\sum_{i=1}^{N} d^{2}\left(\Psi_{\lambda}^{i-1} x_{n}, \Psi_{\lambda}^{i} x_{n}\right) .
\end{aligned}
$$

Using $\left(z_{n}\right)$ in (3.2), we get

$$
d\left(z_{n}, p\right) \leq d\left(V_{N} y_{n}, p\right) \leq d\left(y_{n}, p\right) \leq d\left(x_{n}, p\right),
$$

which together the definition of $\left(x_{n+1}\right)$ implies that

$$
\begin{aligned}
d\left(x_{n+1}, p\right) & =\alpha_{n} d\left(u_{n}, p\right)+\beta_{n} d\left(x_{n}, p\right)+\sigma_{n} d\left(z_{n}, p\right) \\
& \leq \alpha_{n} d\left(u_{n}, p\right)+\left(\alpha_{n}+\sigma_{n}\right) d\left(x_{n}, p\right) \\
& =\left(1-\alpha_{n}\right) d\left(x_{n}, p\right)+\alpha_{n} d\left(u_{n}, p\right) .
\end{aligned}
$$

Since $\left\{u_{n}\right\}$ is bounded, there exists $M>0$ such that $\sup d\left(u_{n}, p\right) \leq M$. Letting $M^{*}=\max \left\{d\left(x_{1}, p\right)\right.$, $M\}$ for all $n \in \mathbb{N}$ implies that $d\left(x_{1}, p\right) \leq M^{*}$. Suppose that, for some $t \in \mathbb{N}, d\left(x_{t}, p\right) \leq M^{*}$, then

$$
\begin{aligned}
d\left(x_{n+1}, p\right) & \leq\left(1-\alpha_{t}\right) d\left(x_{t}, p\right)+\alpha_{t} d\left(x_{t}, p\right) \\
& =\left(1-\alpha_{t}\right) M^{*}+\alpha_{t} M^{*}=M^{*}
\end{aligned}
$$

By induction, we obtain that $d\left(x_{n}, p\right) \leq M^{*}$ for all $n \in \mathbb{N}$. Hence $\left\{x_{n}\right\}$ is bounded. From Lemma 2.1(ii), we obtain

$$
\begin{aligned}
d^{2}\left(x_{n+1}, p\right) & =d^{2}\left(\alpha_{n} u_{n} \oplus \beta_{n} x_{n} \oplus \sigma_{n} z_{n}, p\right) \\
& \leq d^{2}\left[\left(1-\sigma_{n}\right)\left(\frac{\alpha_{n}}{1-\sigma_{n}} u_{n} \oplus \frac{\beta_{n}}{1-\sigma_{n}} x_{n}\right) \oplus \sigma_{n} z_{n}, p\right] \\
& \leq\left(1-\sigma_{n}\right) d^{2}\left(\frac{\alpha_{n}}{1-\sigma_{n}} u_{n} \oplus \frac{\beta_{n}}{1-\sigma_{n}} x_{n}, p\right)+\sigma_{n} d^{2}\left(z_{n}, p\right) \\
& \leq \alpha_{n} d^{2}\left(u_{n}, p\right)+\beta_{n} d^{2}\left(x_{n}, p\right)-\frac{\alpha_{n} \beta_{n}}{1-\sigma_{n}} d^{2}\left(u_{n}, z_{n}\right)+\sigma_{n} d^{2}\left(y_{n}, p\right) \\
& \leq \alpha_{n} d^{2}\left(u_{n}, p\right)+\beta_{n} d^{2}\left(x_{n}, p\right)+\sigma_{n} d^{2}\left(x_{n}, p\right)-\sigma_{n} \sum_{i=1}^{N} d^{2}\left(\Psi_{\lambda}^{i-1} x_{n}, \Psi_{\lambda}^{i} x_{n}\right) \\
& \leq\left(1-\alpha_{n}\right) d^{2}\left(x_{n}, p\right)+\alpha_{n} d^{2}\left(u_{n}, p\right)-\sigma_{n} \sum_{i=1}^{N} d^{2}\left(\Psi_{\lambda}^{i-1} x_{n}, \Psi_{\lambda}^{i} x_{n}\right) .
\end{aligned}
$$

We divide the remaining proof in two cases. 
Case 1. Assume that $\left\{d\left(x_{n}, p\right)\right\}_{n=1}^{\infty}$ is a non-increasing sequence of a real numbers. Since $\left\{d\left(x_{n} \cdot p\right)\right\}_{n=1}^{\infty}$ is bounded, then its limit exists. With the fact that $\alpha_{n} \rightarrow 0$ as $n \rightarrow \infty$ and $\sigma_{n}>0$, (3.4) gives

$$
\sum_{i=1}^{N} d^{2}\left(\Psi_{\lambda}^{i=1} x_{n}, \Psi_{\lambda}^{i} x_{n}\right) \leq d^{2}\left(x_{n}, p\right)-d^{2}\left(x_{n+1}, p\right)+\alpha_{n} d^{2}\left(u_{n}, p\right)
$$

and

$$
\lim _{n \rightarrow \infty} \sum_{i=1}^{N} d^{2}\left(\Psi_{\lambda}^{i=1} x_{n}, \Psi_{\lambda}^{i} x_{n}\right)=0
$$

Note that $d^{2}\left(\Psi_{\lambda}^{i-1} x_{n}, \Psi_{\lambda}^{i} x_{n}\right)$ is nonnegative for each $i=1,2, \cdots, N$. Hence, for each $i=1,2, \ldots, N$, we obtain

$$
\lim _{n \rightarrow \infty} d\left(\Psi_{\lambda}^{i-1} x_{n}, \Psi_{\lambda}^{i} x_{n}\right)=0
$$

Using $\left(y_{n}\right)$ in (3.2) and (3.5), we get

$$
d\left(y_{n}, x_{n}\right) \leq \sum_{i=1}^{N} d\left(\Psi_{\lambda}^{i-1} x_{n}, \Psi_{\lambda}^{i} x_{n}\right) \rightarrow 0, \text { as } n \rightarrow \infty
$$

It follows from (3.2) that

$$
\begin{aligned}
d^{2}\left(x_{n+1}, p\right) & =d^{2}\left(\alpha_{n} u_{n} \oplus \beta_{n} x_{n} \oplus \sigma_{n} z_{n}, p\right) \\
& \leq d^{2}\left[\left(1-\sigma_{n}\right)\left(\frac{\alpha_{n}}{1-\sigma_{n}} u_{n} \oplus \frac{\beta_{n}}{1-\sigma_{n}} x_{n}\right) \oplus \sigma_{n} z_{n}, p\right] \\
& \leq\left(1-\sigma_{n}\right) d^{2}\left[\frac{\alpha_{n}}{1-\sigma_{n}} u_{n} \oplus \frac{\beta_{n}}{1-\sigma_{n}} x_{n}\right]+\sigma_{n} d^{2}\left(z_{n}, p\right) \\
& \leq \alpha_{n} d^{2}\left(u_{n}, p\right)+\beta_{n} d^{2}\left(x_{n}, p\right)-\frac{\alpha_{n} \beta_{n}}{1-\sigma_{n}} d^{2}\left(u_{n}, x_{n}\right)+\sigma_{n} d^{2}\left(z_{n}, p\right) \\
& \leq\left(1-\alpha_{n}\right) d^{2}\left(x_{n}, p\right)+\alpha_{n} d^{2}\left(u_{n}, p\right)-\frac{\alpha_{n} \beta_{n}}{1-\sigma_{n}} d^{2}\left(u_{n}, x_{n}\right),
\end{aligned}
$$

which implies that

$$
\frac{\alpha_{n} \beta_{n}}{1-\sigma_{n}} d^{2}\left(u_{n}, x_{n}\right) \leq d^{2}\left(x_{n}, p\right)-d^{2}\left(x_{n+1}, p\right)+\alpha_{n} d^{2}\left(x_{n}, p\right) .
$$

Hence,

$$
\lim _{n \rightarrow \infty} d\left(u_{n}, x_{n}\right)=0
$$


Also, using Lemma 2.1(ii), we can get that

$$
\begin{aligned}
d^{2}\left(x_{n+1}, p\right) \leq & d^{2}\left(\left(1-\sigma_{n}\right)\left(\frac{\alpha_{n}}{1-\sigma_{n}} u_{n} \oplus \frac{\beta_{n}}{1-\sigma_{n}} x_{n}\right) \oplus \sigma_{n} z_{n}, p\right) \\
\leq & \left(1-\sigma_{n}\right) d^{2}\left(\frac{\alpha_{n}}{1-\sigma_{n}} u_{n} \oplus \frac{\beta_{n}}{1-\sigma_{n}} x_{n}, p\right)+\sigma_{n} d^{2}\left(z_{n}, p\right) \\
& -\sigma_{n}\left(1-\sigma_{n}\right) d^{2}\left(\frac{\alpha_{n}}{1-\sigma_{n}} u_{n} \oplus \frac{\beta_{n}}{1-\sigma_{n}} x_{n}, z_{n}\right) \\
\leq & \alpha_{n} d^{2}\left(u_{n}, p\right)+\beta_{n} d^{2}\left(x_{n}, p\right)+\sigma_{n} d^{2}\left(z_{n}, p\right) \\
& -\sigma_{n}\left(1-\sigma_{n}\right) d^{2}\left(\frac{\alpha_{n}}{1-\sigma_{n}} u_{n} \oplus \frac{\beta_{n}}{1-\sigma_{n}} x_{n}, z_{n}\right) \\
\leq & d^{2}\left(x_{n}, p\right)+\alpha_{n} d^{2}\left(u_{n}, p\right)-\sigma_{n}\left(1-\sigma_{n}\right) d^{2}\left(\frac{\alpha_{n}}{1-\sigma_{n}} u_{n} \oplus \frac{\beta_{n}}{1-\sigma_{n}} x_{n}, z_{n}\right) .
\end{aligned}
$$

Therefore,

$$
\sigma_{n}\left(1-\sigma_{n}\right) d^{2}\left(\frac{\alpha_{n}}{1-\sigma_{n}} u_{n} \oplus \frac{\beta_{n}}{1-\sigma_{n}} x_{n}, z_{n}\right) \leq d^{2}\left(x_{n}, p\right)-d^{2}\left(x_{n+1}, p\right)+\alpha_{n} d^{2}\left(u_{n}, p\right)
$$

and

$$
\lim _{n \rightarrow \infty} d\left(\frac{\alpha_{n}}{1-\sigma_{n}} u_{n} \oplus \frac{\beta_{n}}{1-\sigma_{n}} x_{n}, z_{n}\right)=0
$$

On the other hand, we obtain from (3.7) and (3.8) that

$$
\begin{aligned}
d\left(z_{n}, x_{n}\right) & \leq d\left(z_{n}, \frac{\alpha_{n}}{1-\sigma_{n}} u_{n} \oplus \frac{\beta_{n}}{1-\sigma_{n}} x_{n}\right)+d\left(\frac{\alpha_{n}}{1-\sigma_{n}} u_{n} \oplus \frac{\beta_{n}}{1-\sigma_{n}} x_{n}, x_{n}\right) \\
& \leq d\left(z_{n}, \frac{\alpha_{n}}{1-\sigma_{n}} u_{n} \oplus \frac{\beta_{n}}{1-\sigma_{n}} x_{n}\right)+\frac{\alpha_{n}}{1-\sigma_{n}} d\left(u_{n}, x_{n}\right)
\end{aligned}
$$

Hence,

$$
\lim _{n \rightarrow \infty} d\left(z_{n}, x_{n}\right)=0
$$

We obtain from (3.6) and (3.9) that

$$
d\left(y_{n}, z_{n}\right) \leq d\left(y_{n}, x_{n}\right)+d\left(x_{n}, z_{n}\right) \rightarrow 0, \text { as } n \rightarrow \infty .
$$

From (3.2), (3.8) and (3.9), we get

$$
d\left(x_{n+1}, x_{n}\right) \leq \alpha_{n} d\left(u_{n}, x_{n}\right)+\beta_{n} d\left(x_{n}, x_{n}\right)+\sigma_{n} d\left(z_{n}, x_{n}\right) \rightarrow 0, n \rightarrow \infty
$$


Furthermore, since $S_{i}$ is $k_{i}$-demimetric mapping for each $i \in\{1,2, \ldots, N\}$ with $k=\max \left\{k_{i}\right\} \leq 0$, then

$$
\begin{aligned}
\left\langle\overrightarrow{y_{n} z_{n}}, \overrightarrow{y_{n} \vec{p}}\right\rangle & =-\left\langle\overrightarrow{z_{n} y_{n}}, \overrightarrow{y_{n} \vec{p}}\right\rangle \\
& =-\left\langle\left((1-\gamma) y_{n} \oplus \gamma W_{N} y_{n}\right) y_{n}, \overrightarrow{y_{n} \vec{p}}\right\rangle \\
\geq & -(1-\gamma)\left\langle\overrightarrow{y_{n} y_{n}}, \overrightarrow{y_{n} \vec{p}}\right\rangle-\gamma\left\langle\overrightarrow{W_{N} y_{n} y_{n}}, \overrightarrow{y_{n} \vec{p}}\right\rangle \\
\geq & -\gamma\left\langle\overrightarrow{W_{N} y_{n} y_{n}}, \overrightarrow{y_{n} \vec{p}}\right\rangle \\
\geq & -\gamma\left\langle\bigoplus_{i=1}^{N} \xi_{i} S_{i} y_{n} y_{n}, \overrightarrow{y_{n} \vec{p}}\right\rangle \\
\geq & -\gamma \sum_{i=1}^{N} \xi_{i}\left\langle\overrightarrow{S_{i} y_{n} y_{n}}, \overrightarrow{y_{n} \vec{p}}\right\rangle-\frac{1}{2} \gamma \sum_{i=1}^{N} \alpha_{i} d^{2}\left(S_{i} y_{n}, y_{n}\right) \\
\geq & \gamma \sum_{i=1}^{N} \frac{1-k_{i}}{2} \xi_{i} d^{2}\left(S_{i} y_{n}, y_{n}\right)-\frac{1}{2} \gamma \sum_{i=1}^{N} \xi_{i} d^{2}\left(S_{i} y_{n}, y_{n}\right) \\
& =\gamma \sum_{i=1}^{N} \frac{-k_{i}}{2} \xi_{i} d^{2}\left(S_{i} y_{n}, y_{n}\right) \\
\geq & \frac{-k}{2} \gamma \sum_{i=1}^{N} \xi_{i} d^{2}\left(S_{i} y_{n}, y_{n}\right) .
\end{aligned}
$$

Therefore

$$
\begin{aligned}
\frac{-k}{2} \gamma \sum_{i=1}^{N} \xi_{i} d^{2}\left(S_{i} y_{n}, y_{n}\right) & \leq\left\langle\overrightarrow{y_{n} z_{n}}, \overrightarrow{y_{n} \vec{p}}\right\rangle \\
& \leq d\left(y_{n}, z_{n}\right) d\left(y_{n}, p\right) .
\end{aligned}
$$

Since $\left\{y_{n}\right\}$ is bounded, $k \leq 0$, and $\gamma, \xi_{i} \in(0,1)$ for all $n \geq 1$ and $i \in\{1,2, \ldots, N\}$, then we find from (3.10) and (3.12) that

$$
\lim _{n \rightarrow \infty} d\left(S_{i} y_{n}, y_{n}\right)=0, \text { for } i \in\{1,2, \ldots, N\} .
$$

Now, since $\left\{x_{n}\right\}$ is bounded and $X$ is complete CAT(0) spaces, we conclude from Lemma 2.6 that there exists a subsequence $\left\{x_{n_{j}}\right\}$ of $\left\{x_{n}\right\}$ such that $\Delta-\lim x_{n_{j}}=v \in X$. By (3.6), we get $\Delta$-lim $y_{n_{j}}=v$. With (3.13) and the fact that $S_{i}$ is $\Delta$-demiclosed at 0 , for each $i \in\{1,2 \ldots, N\}$, we obtain that $v \in \bigcap_{i=1}^{N} F\left(S_{i}\right)=\bigcap_{i=1}^{N} F\left(T_{i}\right)$. Furthermore, $\Psi_{\lambda}^{i}$ is firmly nonexpansive, in particular, it is nonexpansive for each $i=1,2, \ldots, N$. Hence by (3.6), we obtain that $v \in \bigcap_{i=1}^{N} A_{i}^{-1}(0)$. Therefore, $v \in \bigcap_{i=1}^{N} F\left(T_{i}\right) \cap\left(\bigcap_{i=1}^{N} A_{i}^{-1}(0)\right)=\Upsilon$. Thus, from Lemma 2.5, we get

$$
\limsup _{n \rightarrow \infty}\left\langle\overrightarrow{u v}, \overrightarrow{x_{n} \vec{v}}\right\rangle \leq 0 \text {. }
$$

Letting $w_{n}:=\frac{\beta_{n}}{1-\alpha_{n}} x_{n} \oplus \frac{\sigma_{n}}{1-\alpha_{n}} z_{n}$, we have

$$
\begin{aligned}
\left\langle\overrightarrow{u_{n} \vec{v}}, \overrightarrow{w_{n} \vec{v}}\right\rangle & =\left\langle\overrightarrow{u_{n} \vec{v}}, \overrightarrow{w_{n}} \overrightarrow{x_{n}}\right\rangle+\left\langle\overrightarrow{u_{n} \vec{v}}, \overrightarrow{x_{n} \vec{v}}\right\rangle \\
& \leq d\left(\overrightarrow{u_{n}, v}\right) d\left(w_{n}, x_{n}\right)+\left\langle\overrightarrow{u_{n} u}, \overrightarrow{x_{n} \vec{v}}\right\rangle+\left\langle\overrightarrow{u v}, \overrightarrow{x_{n} \vec{v}}\right\rangle \\
& \leq \frac{\beta_{n}}{1-\alpha_{n}} d\left(u_{n}, v\right) d\left(x_{n}, z_{n}\right)+d\left(u_{n}, u\right) d\left(x_{n}, v\right)+\left\langle\overrightarrow{u \vec{v}}, \overrightarrow{x_{n} \vec{v}}\right\rangle .
\end{aligned}
$$


Therefore, in view of the fact that $u_{n} \rightarrow u$ as $n \rightarrow \infty$ with (3.9) and (3.14), we obtain

$$
\limsup _{n \rightarrow \infty}\left\langle\overrightarrow{u_{n} v}, \overrightarrow{w_{n} v}\right\rangle \leq 0
$$

Also,

$$
\begin{aligned}
d\left(w_{n}, v\right) & =d\left(\frac{\beta_{n}}{1-\alpha_{n}} x_{n} \oplus \frac{\sigma_{n}}{1-\alpha_{n}} z_{n}, v\right) \\
& \leq \frac{\beta_{n}}{1-\alpha_{n}} d\left(x_{x}, v\right)+\frac{\sigma_{n}}{1-\alpha_{n}} d\left(z_{n, v}\right) \\
& \leq \frac{\beta_{n}}{1-\alpha_{n}} d\left(x_{n}, v\right)+\frac{\sigma_{n}}{1-\alpha_{n}} d\left(x_{n, v}\right) \\
& =d\left(x_{n}, v\right) .
\end{aligned}
$$

Finally, we show that $x_{n} \rightarrow v$. Using(3.2), and letting $\vartheta_{n}:=\alpha_{n} v \oplus\left(1-\alpha_{n}\right) z_{n}$ and $x_{n+1}=$ $\alpha_{n} u_{n} \oplus\left(1-\alpha_{n}\right) w_{n}$, we conclude from Lemma 2.14 and Lemma 2.15 that

$$
\begin{aligned}
d^{2}\left(x_{n+1}, v\right) & \leq d^{2}\left(\vartheta_{n}, v\right)+2\left\langle\overrightarrow{x_{n+1} \vartheta_{n}}, \overrightarrow{x_{n+1} \vec{v}}\right\rangle \\
& \leq\left(1-\alpha_{n}\right) d^{2}\left(w_{n}, v\right)+2\left\langle\overrightarrow{\vartheta_{n} x_{n+1}}, \overrightarrow{v x_{n+1}}\right\rangle \\
& \leq\left(1-\alpha_{n}\right) d^{2}\left(x_{n}, v\right)+2 \alpha_{n}\left\langle\overrightarrow{u_{n} v}, \overrightarrow{w_{n} v}\right\rangle .
\end{aligned}
$$

Therefore

$$
d^{2}\left(x_{n+1}, v\right) \leq\left(1-\alpha_{n}\right) d^{2}\left(x_{n}, v\right)+2 \alpha_{n}\left\langle\overrightarrow{u_{n} v}, \overrightarrow{w_{n}} \vec{v}\right\rangle .
$$

From (3.15), (3.16) and Lemma 2.16, we obtain $d\left(x_{n}, v\right) \rightarrow 0$ as $n \rightarrow \infty$, that is, $x_{n} \rightarrow v$ as $n \rightarrow \infty$.

Case 2. Suppose that $\left\{d\left(x_{n}, p\right)\right\}_{n=1}^{\infty}$ is a not monotone decreasing real sequence. Set $\Upsilon_{n}:=$ $d\left(x_{n}, x^{*}\right)$ for all $n \geq 1$. Then, there exists a subsequence $\Upsilon_{n_{s}}$ of $\Upsilon_{n}$ such that $\Upsilon_{n_{s}}<\Upsilon_{n_{s}+1}$ for all $k \geq 1$. Now, define $\tau: \mathbb{N} \rightarrow \mathbb{N}$ by

$$
\tau(n)=\max \left\{k \leq n: \Upsilon_{k}<\Upsilon_{k+1}\right\} .
$$

It follows from Lemma 2.17 that $\Upsilon_{\tau(n)} \leq \Upsilon_{\tau(n)+1}$. Using (3.4), we get

$$
\sigma_{\tau(n)} \sum_{i=1}^{N} d^{2}\left(\Psi_{\lambda}^{i-1} x_{\tau(n)}, \Psi_{\lambda}^{i} x_{\tau(n)}\right) \leq d^{2}\left(x_{\tau(n)}, v\right)-d^{2}\left(x_{\tau(n)+1}, v\right)+\alpha_{\tau(n)} d^{2}\left(u_{\tau(n)}, v\right) .
$$

Now, $\alpha_{\tau(n)} \rightarrow 0$ as $n \rightarrow \infty$ gives

$$
\lim _{n \rightarrow \infty} \sum_{i=1}^{N} d^{2}\left(\Psi_{\lambda}^{i-1} x_{\tau(n)}, \Psi_{\lambda}^{i} x_{\tau(n)}\right)=0 .
$$

Following an argument similar to the one in Case 1, we obtain

$$
\lim _{n \rightarrow \infty} d\left(y_{\tau(n)}, x_{\tau(n)}\right)=0, \lim _{n \rightarrow \infty} d\left(y_{\tau(n)}, z_{\tau(n)}\right)=0, \lim _{n \rightarrow \infty} d\left(u_{\tau(n)}, x_{\tau(n)}\right)=0
$$

and

$$
\lim _{n \rightarrow \infty} d\left(x_{\tau(n)+1}, x_{\tau(n)}\right)=0=\lim _{n \rightarrow \infty} d\left(S_{i} y_{\tau(n)}, y_{\tau(n)}\right) .
$$

Following the similar argument of proof in Case 1, we get

$$
\left\langle\overrightarrow{u_{\tau n} p}, \overrightarrow{w_{\tau(n)} p}\right\rangle \leq 0 \text {. }
$$


From (3.16), we have

$$
d^{2}\left(x_{\tau(n)+1}, p\right) \leq\left(1-\alpha_{\tau(n)}\right) d^{2}\left(x_{\tau(n)}, p\right)+2 \alpha_{\tau(n)}\left\langle\overrightarrow{u_{\tau(n)} p}, \overrightarrow{w_{\tau(n)} p}\right\rangle .
$$

Since $d^{2}\left(x_{\tau(n)}, p\right)<d^{2}\left(x_{\tau(n)+1}, p\right)$, then

$$
\begin{aligned}
\alpha_{\tau(n)} d^{2}\left(x_{\tau(n)}, p\right) \leq & d^{2}\left(x_{\tau(n)}, p\right)-d^{2}\left(x_{\tau(n)+1}, p\right) \\
& +2 \alpha_{\tau(n)}\left\langle\overrightarrow{u_{\tau(n)} p}, \overrightarrow{w_{\tau(n)} p}\right\rangle \\
< & 2 \alpha_{\tau(n)}\left\langle\overrightarrow{u_{\tau n} p}, \overrightarrow{w_{\tau(n)} p}\right\rangle .
\end{aligned}
$$

Using the fact that $\alpha_{\tau(n)}>0$, we obtain

$$
d^{2}\left(x_{\tau(n)}, p\right)<2\left\langle\overrightarrow{u_{\tau n} p}, \overrightarrow{w_{\tau(n)}} \vec{p}\right\rangle .
$$

Since $\limsup _{n \rightarrow \infty}\left\langle\overrightarrow{u_{\tau n} p}, \overrightarrow{w_{\tau(n)} p}\right\rangle \leq 0$, then

$$
\limsup _{n \rightarrow \infty} d^{2}\left(x_{\tau(n)}, p\right) \leq 0 .
$$

Hence, $\lim _{n \rightarrow \infty} d\left(x_{\tau(n)}, p\right)=0$. Since $\lim _{n \rightarrow \infty} d\left(x_{\tau(n)+1}, x_{\tau(n)}\right)=0$, then

$$
\lim _{n \rightarrow \infty} d\left(x_{\tau(n)}, p\right)=\lim _{n \rightarrow \infty} d\left(x_{\tau(n)+1}, p\right)=0 .
$$

Therefore, by Lemma 2.17, we obtain $d\left(x_{n}, p\right) \leq d\left(x_{\tau(n)+1}, p\right) \rightarrow 0$ as $n \rightarrow \infty$. Hence $x_{n} \rightarrow p$ as $n \rightarrow \infty$.

Let $X$ be complete CAT(0) space and let $X^{*}$ be its dual space. Let $f: X \rightarrow(-\infty, \infty]$ be a proper lower semicontinuous and convex function with domain $\mathbb{D}(f):=\{x \in X: f(x)<+\infty\}$. Then the subdifferential of $f$ is a set-valued function $\partial f: X \rightarrow 2^{X^{*}}$ is defined by

$$
\partial f(x)= \begin{cases}\left\{x^{*} \in X^{*}: f(z)-f(x) \geq\left\langle x^{*}, \overrightarrow{x z}\right\rangle,\right. & (z \in X)\}, \text { if } x \in \mathbb{D}(f), \\ \emptyset & \text { otherwise }\end{cases}
$$

It has been shown in [14] that

(1) $\partial f$ is a monotone operator;

(2) $\partial f$ satisfies the range condition. That is, $\mathbb{D}\left(J_{\lambda}^{\partial f}\right)=X$ for all $\lambda>0$;

(3) $f$ attains its minimum at $x \in X$ if and only if $0 \in \partial f(x)$.

Now, we consider the following Minimization Problem (MP), which consists of finding $x \in X$ such that

$$
f(x)=\min _{y \in X} f(y) .
$$

From Theorem 3.1, we obtain the following result.

Corollary 3.1. Let $X$ be a complete $C A T(0)$ space with dual $X^{*}$ and let $C$ be a nonempty closed and convex subset of $X$. Let $\left\{T_{i}\right\}_{i=1}^{N}: C \rightarrow X$ be a finite family of $\theta_{i}$-generalized demimetric mappings and $\Delta$-demiclosd at 0 with $\theta_{i} \in(0, \infty)$ for each $i \in\{1,2, \ldots, N\}$. Let $f_{i}: X \rightarrow(-\infty, \infty]$ $(i=1,2, \ldots, N)$ be a finite family of proper, lower semicontinuous and convex functions. Assume that $\Upsilon:=\bigcap_{i=1}^{N} F\left(T_{i}\right) \cap\left(\bigcap_{i=1}^{N} \partial f_{i}^{-1}(0)\right) \neq \emptyset$. Let $\left\{u_{n}\right\}$ be a sequence in $X$ such that $u_{n} \rightarrow u \in X$. 
Assume $k \in(0, \gamma)$ with $\gamma \in(0,1)$ and $\theta_{i} k>0$. For any $x_{1} \in X$, let $\left\{x_{n}\right\}$ in $X$ be a sequence generated by

$$
\left\{\begin{array}{l}
y_{n}=J_{\lambda}^{\partial f_{N}} \circ J_{\lambda}^{\partial f_{N-1}} \circ \cdots \circ J_{\lambda}^{\partial f_{2}} \circ J_{\lambda}^{\partial f_{1}} x_{n}, \\
z_{n}=(1-\gamma) y_{n} \oplus \gamma\left[\oplus_{i=1}^{N} \xi_{i}\left((1-k) \oplus k T_{i}\right) y_{n}\right] \\
x_{n+1}=\alpha_{n} u_{n} \oplus \beta_{n} x_{n} \oplus \sigma_{n} z_{n},
\end{array}\right.
$$

where $\lambda \in(0, \infty),\left\{\alpha_{n}\right\},\left\{\sigma_{n}\right\},\left\{\beta_{n}\right\}$ and $\left\{\xi_{i}\right\}_{i=1}^{N}$ are sequences in $(0,1)$ satisfying the following conditions

(i) $\lim _{n \rightarrow \infty} \alpha_{n}=0$ and $\sum_{i=1}^{\infty} \alpha_{n}=\infty$;

(ii) $\alpha_{n}+\beta_{n}+\sigma_{n}=1$.

Then $\left\{x_{n}\right\}$ converges strongly to $x^{*} \in \Upsilon$.

\section{Applications}

In this section, using Theorem 3.1, we obtain new strong convergence theorems in complete CAT(0) space.

Definition 4.1. [41] Let $C$ be a nonempty subset of a CAT(0) space $X$. A mapping $T: C \rightarrow X$ is called a strict pseudo-contraction if there exists a constant $0 \leq \delta<1$ such that

$$
d^{2}(T x, T y) \leq d^{2}(x, y)+4 \delta\left(\frac{1}{2} x \oplus \frac{1}{2} T y, \frac{1}{2} T x \oplus \frac{1}{2} y\right)
$$

for all $x, y \in C$. If (4.1) holds, we also say that $T$ is a $\delta$-strict pseudo-contraction.

The definition of pseudo-contractions finds its origin in Hilbert spaces. Note that the class of strict pseudo-contractions strictly includes the class of nonexpansive mappings. That is, $T$ is nonexpansive if and only if $T$ is a 0 -strict pseudo-contraction.

Lemma 4.1. [41] Let $C$ be a nonempty, closed and convex subset of a Hadamard space $X$ and let $T: C \rightarrow X$ be $\delta$-strict pseudocontraction. Define $T_{\delta}: C \rightarrow X$ by $T_{\delta} x=\delta x \oplus(1-\delta) T x$. Then $T_{\delta}$ is nonexpansive mapping and $F(T)=F\left(T_{\delta}\right)$.

Lemma 4.2. Let $C$ be a nonempty closed and convex subset of a Hadamard space $X$. Let $S$ : $C \rightarrow C$ be a nonexpansive mapping and let $T: C \rightarrow C$ be a $\delta$-strict pseudo-contraction such that $F(S) \cap F(T) \neq \emptyset$. Let $W_{\alpha}=((1-\alpha) I \oplus \alpha T) S x$, for any $x \in C$, where $0<\alpha<\frac{1}{1+\delta}$ and $\delta \in(0,1)$. Then $F\left(W_{\alpha}\right)=F(S) \cap F(T)$. Furthermore, if $F\left(W_{\alpha}\right) \neq \emptyset$, then $W_{\alpha}$ is 2-generalized demimetric.

Proof. First, we show that $F\left(W_{\alpha}\right)=F(S) \cap F(T)$. It is easy to prove that $F(S) \cap F(T) \subseteq F\left(W_{\alpha}\right)$. Next, we show that $F\left(W_{\alpha}\right) \subseteq F(S) \cap F(T)$ for any $x \in F\left(W_{\alpha}\right)$ and $y \in F(S) \cap F(T)$

$$
\begin{aligned}
d^{2}(x, y)= & \left.d^{2}((1-\alpha) I \oplus \alpha T) S x, y\right) \\
= & (1-\alpha) d^{2}(S x, y)+\alpha d^{2}(T S x, y)-\alpha(1-\alpha) d^{2}(S x, T S x) \\
= & d^{2}(S x, y)-\alpha d^{2}(S x, y) \\
& +\alpha d^{2}(T S x, y)-\alpha(1-\alpha) d^{2}(S x, T S x) .
\end{aligned}
$$


Since $T$ is $\delta$-strictly pseudocontractive, we obtain

$$
\begin{aligned}
d^{2}(T S x, y) \leq & d^{2}(S x, y)+4 \delta d^{2}\left(\frac{1}{2} S x \oplus \frac{1}{2} y, \frac{1}{2} T S x \oplus \frac{1}{2} y\right) \\
\leq & d^{2}(S x, y)+\delta\left[d^{2}(S x, y)+d^{2}(T S x, y)+d^{2}(S x, T S x)\right. \\
& \left.+d^{2}(y, y)-d^{2}(S x, y)-d^{2}(y, T S x)\right] \\
= & d^{2}(S x, y)+\delta d^{2}(S x, y)+\delta d^{2}(T S x, y) \\
& +\delta d^{2}(S x, T S x)-\delta d^{2}(S x, y)-\delta d^{2}(y, T S x) \\
= & d^{2}(S x, y)+\delta d^{2}(S x, T S x) .
\end{aligned}
$$

By (4.2) and (4.3), we obtain

$$
\begin{aligned}
d(x, y) & \leq d^{2}(S x, y)+\alpha \delta d^{2}(S x, T S x)-\alpha(1-\alpha) d^{2}(S x, T S x) \\
& \leq d^{2}(x, y)-\alpha(1-\alpha(1+\delta)) d^{2}(S x, T S x)
\end{aligned}
$$

Hence,

$$
\alpha(1-\alpha(1+\delta)) d^{2}(S x, T S x) \leq 0 .
$$

By the virtue of $0<\alpha<\frac{1}{1+\delta}$, we have $\alpha(1-\alpha(1+\delta))>0$ and then

$$
T S x=S x \text {. }
$$

By (4.4), we have

$$
\begin{aligned}
d(x, S x) & =d(((1-\alpha) I \oplus \alpha T) S x, S x) \\
& \leq(1-\alpha) d(S x, S x)+\alpha d(T S x, S x) \\
& \leq \alpha d(x, S x),
\end{aligned}
$$

which implies that

$$
(1-\alpha) d(x, S x) \leq 0
$$

Since $\alpha \in(0,1)$, we have

$$
d(x, S x)=0, \quad \Longrightarrow \quad x=S x .
$$

Therefore, we obtain that $x \in F(S)$. From (4.4) and (4.5), we get $x=S x=T S x=T x$, so $x \in$ $F(T)$. Hence $x \in F(S) \cap F(T)$. So, $F\left(W_{\alpha}\right) \subset F(S) \cap F(T)$ hold.

Next, we show that $W_{\alpha}$ is 2-generalized demimetric. Let $p \in F\left(W_{\alpha}\right)$. Then, $p \in F(S) \cap F(T)$. From Lemma 4.1, we obtain

$$
\begin{aligned}
d^{2}\left(W_{\alpha} x, p\right) & \leq d^{2}([(1-\alpha) I \oplus \alpha T] S x, p) \\
& \leq d^{2}(S x, p) \\
& \leq d^{2}(x, p) .
\end{aligned}
$$

Then, it follows (2.1) and (4.6) that

$$
2\left\langle\overrightarrow{x W_{\alpha} x}, \overrightarrow{p x}\right\rangle+d^{2}(x, p)+d^{2}\left(W_{\alpha} x, x\right) \leq d^{2}(x, p),
$$

thus,

$$
d^{2}\left(W_{\alpha} x, x\right) \leq 2\left\langle\overrightarrow{x W_{\alpha} x}, \overrightarrow{x p}\right\rangle .
$$

Hence, $W_{\alpha}$ is 2-generalized demimetric mapping. This complete the proof. 
Lemma 4.3. [19] Let $C$ be a closed and convex subset of a complete $C A T(0)$ space $X$ and let $T: C \rightarrow X$ be a nonexpansive mapping. Let $\left\{x_{n}\right\}$ be a bounded sequence in $C$ such that $\lim _{n \rightarrow \infty} d\left(T x_{n}, x_{n}\right)=0$ and $\Delta-\lim _{n \rightarrow \infty} x_{n}=p$. Then $p=T p$.

With the help of Lemma 4.2, we obtain the following result.

Theorem 4.1. Let $X$ be a complete $C A T(0)$ space with dual $X^{*}$ and let $C$ be a nonempty closed and convex subset of $X$. Let $S: C \rightarrow C$ be a nonexpansive mapping and let $T: C \rightarrow C$ be a $\delta$-strict pseudo-contraction such that $F(S) \cap F(T) \neq \emptyset$. For $0<\alpha<\frac{1}{1+\delta}$, let $W_{\alpha}:=((1-\alpha) I \oplus \alpha T) S$. Let $A_{i}: X \rightarrow 2^{X^{*}}(i=1,2, \ldots, N)$ be multivalued monotone mappings, which satisfy the range condition. Assume that $\Upsilon:=F(T) \cap F(S) \cap\left(\bigcap_{i=1}^{N} A_{i}^{-1}(0)\right) \neq \emptyset$. Let $\left\{u_{n}\right\}$ be a sequence in $X$ such that $u_{n} \rightarrow u \in X$. For any $x_{1} \in X$, let $\left\{x_{n}\right\}$ in $X$ be a sequence generated by

$$
\left\{\begin{array}{l}
y_{n}=J_{\lambda}^{N} \circ J_{\lambda}^{N-1} \circ \cdots \circ J_{\lambda}^{2} \circ J_{\lambda}^{1} x_{n}, \\
z_{n}=(1-\gamma) y_{n} \oplus \gamma W_{\alpha} y_{n}, \\
x_{n+1}=\alpha_{n} u_{n} \oplus \beta_{n} x_{n} \oplus \sigma_{n} z_{n},
\end{array}\right.
$$

where $\lambda \in(0, \infty), \gamma \in(0,1)$ and $\left\{\alpha_{n}\right\}$, and $\left\{\sigma_{n}\right\},\left\{\beta_{n}\right\}$ are sequences in $(0,1)$ satisfying the following conditions

(i) $\lim _{n \rightarrow \infty} \alpha_{n}=0$ and $\sum_{i=1}^{\infty} \alpha_{n}=\infty$;

(ii) $\alpha_{n}+\beta_{n}+\sigma_{n}=1$.

Then $\left\{x_{n}\right\}$ converges strongly to $x^{*} \in \Upsilon$.

Proof. Since $T$ is $\delta$-strictly pseudo-contractive and $S$ is nonexpansive. From Lemma 4.1, we have that $T_{\alpha}:=(1-\alpha) I \oplus \alpha T$ is nonexpansive. From Lemma 4.3, $(1-\alpha) I \oplus \alpha T$ and $S$ are $\Delta$-demiclosed at zero. If $\lim _{n \rightarrow \infty} d\left(T_{\alpha} x_{n}, x_{n}\right)=0=\lim _{n \rightarrow \infty} d\left(S x_{n}, x_{n}\right)$, then

$$
\begin{aligned}
d\left(W_{\alpha} x_{n}, x_{n}\right) & =d\left(((1-\alpha) I \oplus \alpha T) S x_{n}, x_{n}\right) \\
& \leq d\left(T_{\alpha} S x_{n}, T_{\alpha} x_{n}\right)+d\left(T_{\alpha} x_{n}, x_{n}\right) \\
& \leq d\left(S x_{n}, x_{n}\right)+d\left(T_{\alpha} x_{n}, x_{n}\right) .
\end{aligned}
$$

Hence $\lim _{n \rightarrow \infty} d\left(W_{\alpha} x_{n}, x_{n}\right)=0$, Since $F(T) \cap F(S) \neq \emptyset$, we find from Lemma 4.2 that $W_{\alpha}$ is 2generalized demimetric mapping. We obtain the desired Theorem 3.1.

\section{Acknowledgments}

The authors are grateful to the referees for useful suggestions, which improved the presentation of this paper.

\section{REFERENCES}

[1] T.H. Cuong, J.C. Yao, N.D. Yen, Qualitative properties of the minimum sum-of-squares clustering problem, Optimization, 69 (2020), 2131-2154.

[2] N.T. An, P.D. Dong, X. Qin, Robust feature selection via nonconvex sparsity-based methods, J. Nonlinear Var. Anal. 5 (2021), 59-77.

[3] T. Humphries, M. Loreto, B. Halter, W. O’Keeffe, L. Ramirez, Comparison of regularized and superiorized methods for tomographic image reconstruction, J. Appl. Numer. Optim. 2 (2020), 77-99.

[4] M. Tian, G. Xu, Inertial modified Tseng's extragradient algorithms for solving monotone variational inequalities and fixed point problems, J. Nonlinear Funct. Anal. 2020 (2020), Article ID 35. 
[5] X. Qin, N.T. An, Smoothing algorithms for computing the projection onto a Minkowski sum of convex sets, Comput. Optim. Appl. 74 (2019), 821-850.

[6] B. Martinet, Régularisation d'inéquations variationnelles par approximations successives, Rev. Fr. Inform. Rech. Opér. 4 (1970), 154-158.

[7] R. T. Rockafellar, Monotone operators and the proximal point algorithm, SIAM J. Control Optim. 14 (1976), 877-898.

[8] S.Y. Cho, X. Qin, L. Wang, Strong convergence of a splitting algorithm for treating monotone operators, Fixed Point Theory Appl. 2014 (2014), Article ID 94.

[9] F. U. Oguisis, O. T. Mewomo, Iterative solution of split variational inclusion problem in real Banach space, Afr. Math. 28 (2017), 295-309.

[10] X. Qin, S.Y. Cho, L. Wang, Strong convergence of an iterative algorithm involving nonlinear mappings of nonexpansive and accretive type, Optimization, 67 (2018), 1377-1388.

[11] Y. Shehu, Convergence results of forward-backward algorithms for sum of monotone operators in Banach spaces, Results Math. 74 (2019), 138.

[12] S. Suantai, Y. Shehu, P. Cholamjiak, Nonlinear iterative methods for solving the split common null point problem in Banach spaces, Optim. Methods Softw. 34 (2019), 853-874.

[13] C.C. Okeke, C. Izuchukwu, A strong convergence theorem for monotone inclusion and minimization problems in complete CAT(0) spaces, Optim. Methods Softw. 34 (2019), 1168-1183.

[14] A. B. Kakavandi, M. Amini, Duality and subdifferential for convex functions on complete CAT(0) metric spaces, Nonlinear Anal. 73 (2010), 3450-3455.

[15] H. Khatibzadeh, S. Ranjbar, Monotone operators and the proximal point algorithm in complete CAT(0) metric spaces, J. Aust. Math. Soc. 103 (2017), 70-90.

[16] S. Ranjbar, H. Khatibzadeh, Strong and $\Delta$-convergence to a zero of a monotone operator in $\mathrm{CAT}(0)$ spaces, Mediterr. J. Math. 14 (2017), 56.

[17] C. E. Chidume, A. U. Bello, P. Ndambomve, Strong and $\Delta$-convergence theorems for common fixed points of a finite family of multivalued demicontractive mappings in CAT(0) spaces, Abstr. Appl. Anal. 2014 (2014), 805168

[18] S. Dhompongsa, K. W. Kirk, B. Panyanak, Nonexpansive set-valued mappings in metric and Banach spaces, J. Nonlinear Convex Anal. 8 (2007), 35-45.

[19] W. A. Kirk, B. Panyanak, A concept of convergence in geodesic spaces, Nonlinear Anal. 68 (2008), 36893696.

[20] J. Merryfield, J.D. Stein Jr, Generalization of the Banach contraction principle, J. Math. Anal. Appl. 273 (2002), 112-120.

[21] K.O. Aremu, C. Izuchukwu, G.C. Ugwunnadi, O. T. Mewomo, On the proximal point algorithm and demimetric mapping in CAT(0) space, Demonstr. Math. 51 (2018), 277-294.

[22] G.C. Ugwunnadi, O.C. Collins, V.M. Magagula, A.R. Khan, Monotone inclusion problem and fixed point problem of a generalized demimetric mapping in CAT(0) spaces, Rendiconti del Circolo Matematico di Palermo Series-2 70 (2021), 365-387.

[23] M. R. Bridson, A. Haefilger, Metric Spaces of Non-Positive Curvature, Fundamental Principle of Mathematical Sciences, Springer, Berlin, Germany, 1999.

[24] K. Goebel, S. Reich, Uniform Convexity, Hyperbolic Geometry and Nonexpansive Mappings, Marcel Dekker, New York, 1984.

[25] J. Jost, Nonpositive Curvature: Geometric and Analytic Aspects,Lectures in Mathematics ETH Zürich BirkhNauser, Basel, 1997.

[26] S. Reich, I. Shafrir, Nonexpansive iterations in hyperbolic spaces, Nonlinear Anal. 15 (1990), 537-558.

[27] I. D. Berg, I. G. Nikolaev, Quasilinearization and curvature of Alexandrov spaces, Geom. Dedicata 133 (2008), 195-218.

[28] H. Dehghan, C. Izuchukwu, O. T. Mewomo, D. A. Taba, G. C. Ugwunnadi, Iterative algorithm for a family of monotone inclusion problems in CAT(0) spaces, Quest. Math. 43 (2020), 975-998.

[29] J. Wang, C. Li, G. Lopez, J.C. Yao, Proximal point algorithms on Hadamard manifold: Linear convergence and finite termination, SIAM J. Optim. 26 (2016), 2696-2729. 
[30] S. Dhompongsa, B. Panyanak, On $\triangle$-convergence theorems in CAT(0) spaces, Comput. Math. Appl. 56 (2008), 2572-2579.

[31] S. Dhomponga, W. A. Kirk, B. Sims, Fixed points of uniformly lipschitzian mappings, Nonlinear Anal. 65 (2006), 762-772.

[32] S. Dhompongsa, W.A. Kirk, B. Panyanak, Nonexpansive set-valued mappings in metric and Banach spaces, J. Nonlinear Convex Anal. 8 (2007), 35-45.

[33] B. Nanjaras, B. Panyanak, Demiclosed principle for asymptotically nonexpansive mappings in CAT(0) spaces, Fixed Point Theory Appl. 2010 (2010), 268780.

[34] R. Wangkeeree, P. Preechasilp, Viscosity approximation methods for nonexpansive mappings in CAT(0) spaces, J. Inequal. Appl. 2013 (2013), 93

[35] G. C. Ugwunnadi, C. Izuchukwu, O. T. Mewomo, Strong convergence theorem for monotone inclusion problem in CAT(0) spaces, Afrika Matematika, 30 (2019), 151-169.

[36] B.A. Kakavandi, Weak topologies in complete CAT(0) metric spaces, Proc. Amer. Math. Soc. 141 (2013), 1029-1039.

[37] G. C. Ugwunnadi, Approximating a common fixed points of finite family of demimetric mapping in CAT(0) spaces, Adv. Fixed Point Theory, 9 (2019), 29-44

[38] Y. Li, H. B. Liu, Viscosity approximation methods for the implicit midpoint rule of asymptotically nonexpansive mappings in complete CAT(0) spaces, J. Nonlinear Sci. Appl. 10 (2017), 1270-1280.

[39] H. K. Xu, Iterative algorithms for nonlinear operators, J. London Math. Soc. 66 (2002), 240-256.

[40] P. E. Maingé, Strong convergence of projected subgradient methods for nonsmooth and nonstrictly convex minimization, Set-Valued Anal. 16 (2008), 899-912.

[41] A. R. Tufa, H. Zegeye, M. Thuto, Convergence theorems for non-self mapping CAT(0) spaces, Numer. Funct. Anal. Optim. 38 (2017), 705-722. 